\title{
Mapeamento tridimensional de um paleocanal por eletrorresistividade
}

Paula Rayane Lopes de Andrade ${ }^{1}$, José Agnelo Soares ${ }^{1}$

1 Universidade Federal de Campina Grande

Copyright 2018, SBGf - Sociedade Brasileira de Geofísica

Este texto foi preparado para a apresentação no VIII Simpósio Brasileiro de Geofísica, Salinópolis, 18 a 20 de setembro de 2018. Seu conteúdo foi revisado pelo Comitê Técnico do VIII SimBGf, mas não necessariamente representa a opinião da SBGf ou de seus associados. É proibida a reprodução total ou parcial deste material para propósitos comerciais sem prévia autorização da SBGf.

\section{Resumo}

Este trabalho apresenta o resultado de um levantamento de eletrorresistividade ao longo de um trecho do rio Sucuru, nas proximidades da cidade de Sumé-PB. O objetivo é mapear a ocorrência de sedimentos saturados com água cujo paleocanal principal se constitue numa feição adequada a perfuração de poços produtores de água. Foram registradas seis linhas $2 \mathrm{D}$ as quais foram interpoladas para a geração de um modelo 3D de um trecho da calha do rio. De modo geral, vê-se que há uma zona resistiva, no topo, que corresponde aos sedimentos da zona não-saturada, e outra na base, que corresponde ao topo do embasamento cristalino. Pode-se identificar uma região retilínea e contínua, de baixa resistividade, que corresponde ao principal paleocanal nesse trecho do rio.

\section{Introdução}

O reconhecimento de paleocanais é um elemento importante na construção do processo evolutivo dos sistemas fluviais. Ao longo do tempo processos como alteração climática e intemperismo provocam a realocação e o redimensionamento de canais fluviais. Antigos canais são preenchidos por sedimentos e novos canais surgem como caminhos alternativos ao fluxo de água. Paleocanais fornecem informações sobre 0 paleoclima, possíveis ocorrências minerais associadas à dinâmica fluvial e quanto à favorabilidade hidrogeológica.

Muitas vezes a sua presença não pode ser detectada em superfície, fazendo-se necessário o uso de métodos geofísicos para a sua localização e dimensionamento. Os métodos utilizados no reconhecimento dos paleocanais são variados, tais como o emprego de imagens multiespectrais (Gilvear \& Bryant, 2003), modelos digitais de elevação (Almeida Filho \& Miranda, 2007) e imagens de radar de abertura sintética (Rossetti, 2010). Diversos autores usaram técnicas geofísicas para o reconhecimento de paleocanais. Genau et al (1994) aplicaram o método sísmico de reflexão, de alta resolução e baixa profundidade de investigação, para mapear paleocanais quaternários em Maryland, EUA. Fradelizio et al (2008) utilizaram o imageamento sísmico 3D para identificar as margens e o fundo de um

paleocanal inserido entre 10 e 15 metros de profundidade em uma camada de argila. Islam et al (2016) utilizaram sondagem elétrica vertical e levantamento da condutividade elétrica para mapear um paleocanal no deserto Cholistan do Paquistão e avaliar a qualidade da água subterrânea presente nele.

Os dados hidrogeológicos clássicos têm sido complementados com informação geofísica da subsuperfície. Estas novas informações permitem obter imagens mais precisas dos sistemas aquíferos (Schwinn \& Tezkan 1997; Unsworth et al. 2000; Krivochieva \& Chouteau 2003; Meju et al. 2003; Kafri \& Goldman 2005; Pedersen et al. 2005; Mota \& Monteiro dos Santos 2006). Falgàs et al (2011) caracterizaram a estrutura litológica complexa e a intrusão marinha pela combinação de dados hidrogeológicos, audiomagnetotelúricos (AMT) e modelos de reflexão e de refração sísmica. Dessa forma eles determinaram a espessura e a continuidade lateral dos aquíferos, bem como a sua forma e a profundidade do embasamento. Os modelos gerados revelaram que o caminho principal para a intrusão salina era constituído por um paleocanal soterrado existente na área.

O objetivo deste trabalho é investigar a disposição dos sedimentos saturados em água dispostos ao longo de um trecho da calha do Rio Sucuru, o qual consiste em um rio intermitente localizado na região semi-árida do nordeste brasileiro. As unidades que compõem tal depósito foram mapeadas através da aplicação do método geofísico de eletrorresistividade. A Figura 1 apresenta o mapa de localização da área de estudo, indicada pelo retângulo amarelo, a qual mede $125 \mathrm{~m}$ na direção do eixo $\mathrm{Y}$ por $100 \mathrm{~m}$ na direção do eixo $\mathrm{X}$. A área estudada se encontra dentro de um perímetro irrigado o qual utiliza poços para satisfazer a demanda hídrica. De acordo com Vieira (2002), a largura dos depósitos aluviais que ocorrem no trecho do perímetro irrigado varia entre $100 \mathrm{~m}$ e $350 \mathrm{~m}$ e a espessura do pacote aluvial varia entre um mínimo de $0,45 \mathrm{~m}$ e um máximo de $9,30 \mathrm{~m}$.

\section{Geologia}

As rochas presentes na região são compostas por gnaisses claros com freqüentes intercalações de anfibolitos, calcissilicáticas, com raras formações ferríferas. Podem ocorrer ainda rochas ultramáficas, granulitos e metapiroxenitos (CPRM, 2000). O aquífero existente na área consiste de um aquífero granular livre, não-drenante, composto por grãos de silte, areia e argila.

\section{Método}

Para investigar os sedimentos saturados dispostos ao longo do trecho em estudo foi aplicado o método da eletrorresistividade, através da aquisição de múltiplas SEVs, usando o arranjo Schlumberger de eletrodos. O equipamento utilizado foi um eletrorresistivímetro Bodenseewerk Geosystem model GGA 30, conforme mostrado na Figura 2. 


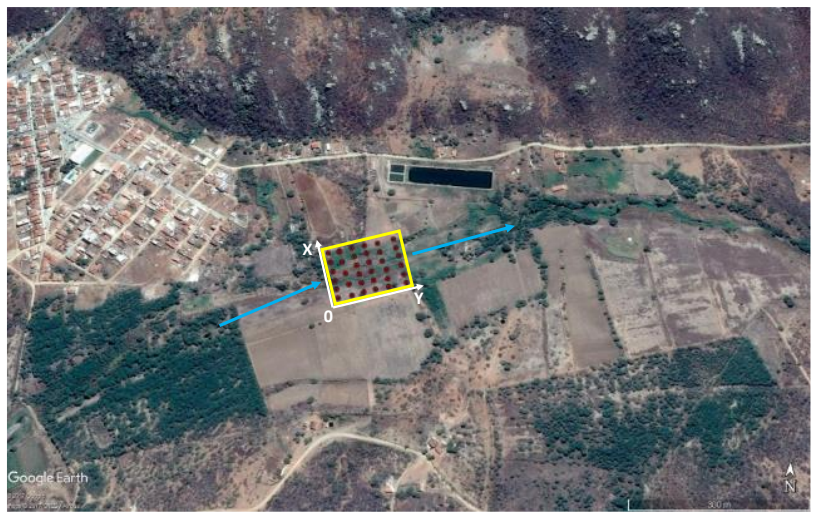

Figura 1 - Mapa de localização da área investigada (retângulo amarelo). As setas azuis indicam o sentido do fluxo do rio. Os círculos vermelhos indicam a localização dos centros das SEVs. A aquisição de dados foi realizada no sentido $0-X$ e $0-Y$. No lado esquerdo do mapa vê-se parte da cidade de Sumé.

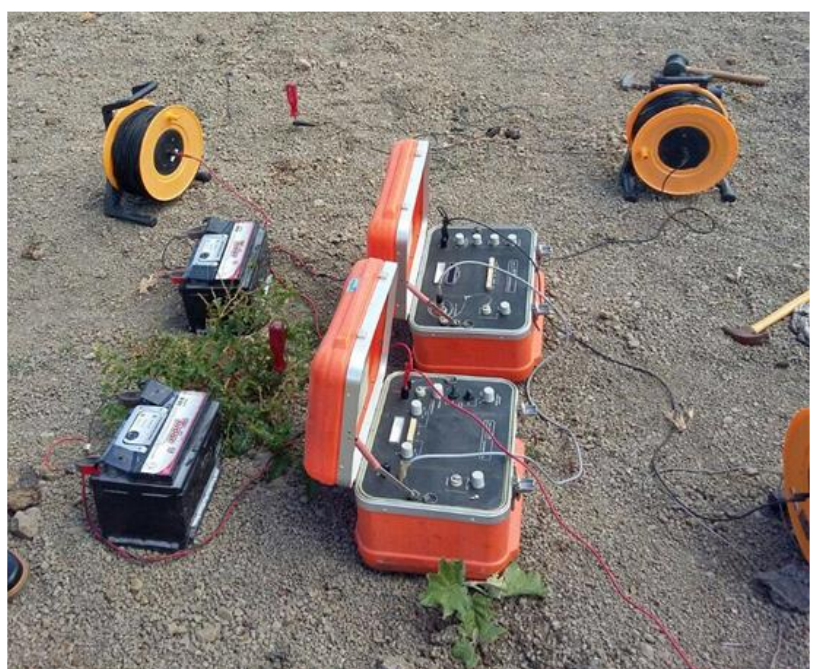

Figura 2 - Equipamentos utilizados na aquisição dos dados de eletrorresistividade.

$\mathrm{Na}$ área investigada, conforme indicado na Figura1, foram feitas seis linhas espaçadas entre si por $25 \mathrm{~m}$, onde para cada linha foram feitas seis SEVs com espaçamento entre elas de $20 \mathrm{~m}$. O espaçamento utilizado entre os eletrodos de corrente foi de $10 \mathrm{~m}$ e entre os eletrodos de potencial foi de $2 \mathrm{~m}$. O tamanho total de cada linha foi de $200 \mathrm{~m}$, e para cada SEV, uma distância máxima de $100 \mathrm{~m}$ entre os eletrodos de corrente.

A aquisição dos dados foi realizada na forma de linhas dispostas na direção perpendicular ao eixo da calha do rio. Cada linha começa na posição $X=-50 \mathrm{~m}$ (ver Figura 1) e termina na posição $X=150 \mathrm{~m}$. No entanto, as seções geoelétricas são geradas apenas na região entre os centros da primeira e da sexta SEV de cada linha, de modo que cada seção começa em $X=0 \mathrm{~m}$ e termina em $X=100 \mathrm{~m}$. As linhas foram registradas para posições $Y$ sucessivamente crescentes, desde $Y=0 \mathrm{~m}$ até $\mathrm{Y}=125$ $\mathrm{m}$.

A topografia do terreno é relativamente plana, apresentando apenas depressões submétricas em áreas localizadas do centro da calha do rio. Tais variações topográficas foram desprezadas neste estudo.

A inversão dos dados foi realizada através do software Res2Dinv para cada linha individual de SEVs aplicando a opção de inversão pelo método dos mínimos quadrados, resultando em seções geoelétricas com profundidade máxima de aproximadamente 20 metros.

Para a interpolação dos dados de resistividade, de modo a criar valores no espaço entre as seções bidimensionais, foi utilizado o software Voxler. Nele foi gerado um modelo tridimensional da área estudada através da aplicação de um processo de discretização do espaço 3D por uma malha de células tridimensionais. Para a interpolação foi aplicado o método do inverso do quadrado da distância com busca anisotrópica de dados. Os raios de busca adotados nas direções $x$, y e $z$ (profundidade), foram respectivamente $25 \mathrm{~m}, 62,5 \mathrm{~m}$ e $5 \mathrm{~m}$. O número mínimo e máximo de dados a considerar dentro do elipsóide de busca foi respectivamente de 3 e 50.

\section{Resultados}

As figuras 3 a 8 apresentam as seções geoelétricas de resistividade obtidas pela inversão dos dados de cada linha registrada. Os erros RMS obtidos na inversão de cada linha são apresentados na Tabela 1. Os erros encontrados, todos abaixo de $30 \%$, foram considerados aceitáveis, sendo ainda observada uma redução considerável no erro para as linhas 03 a 06.

Tabela 1 - Erros RMS obtidos para cada linha de dados.

\begin{tabular}{c|c}
\hline Linha & Erro RMS (\%) \\
\hline 01 & 29,1 \\
\hline 02 & 26,7 \\
\hline 03 & 15,7 \\
\hline 04 & 18,2 \\
\hline 05 & 16,8 \\
\hline 06 & 15,1 \\
\hline
\end{tabular}

De modo geral se observa uma predominância de regiões resistivas na porção superior das seções, assim como, na maioria das seções, na região inferior direita. Por outro lado, a região condutiva se encontra de forma predominante nas regiões esquerda e central das seções geoéletricas.

A Figura 9 apresenta o conjunto de seções geoelétricas como elas são visualizadas no software utilizado para interpolação. Nesta figura todas as seções se encontram em uma mesma escala de cores e se encontram posicionadas em relação ao sistema de eixos.

A Figura 10 apresenta o modelo 3D interpolado para toda a área estudada. Nesta imagem as resistividades apresentadas estão limitadas a 200 ohm.m, pois acima 
deste valor não se espera que ocorram sedimentos saturados por água.

As figuras 11 e 12 apresentam cortes do modelo 3D no plano $X Y$ a profundidades de $10 \mathrm{~m}$ e $17 \mathrm{~m}$, respectivamente. Nelas se observa que os sedimentos saturados de baixa resistividade (cor azul) se concentram ao longo de uma região aproximadamente retilínea na posição $X=24 \mathrm{~m}$. Esta região condutiva indica a posição do principal paleocanal soterrado neste trecho do rio Sucuru. Diferentemente da profundidade máxima indicada por Vieira (2002), a profundidade máxima dos sedimentos ao longo do paleocanal identificado neste trabalho está em torno de 20 metros.

A figura 13 apresenta as superfícies que separam as zonas com resistividade elétrica maiores e menores que 200 ohm.m, uma vez que se considera esse valor como sendo a resistividade máxima esperada para sedimentos saturados com água. De modo geral, vê-se que há uma zona resistiva, no topo, que corresponde aos sedimentos da zona não-saturada, e outra na base, que corresponde ao topo do embasamento cristalino. Próximo ao canto inferior direito vê-se uma região retilínea e contínua, de baixa resistividade, que corresponde ao principal paleocanal nesse trecho do rio.

\section{Conclusões}

Nesse trabalho foi demonstrada a eficiência do método da eletrorresistividade para a identificação e o dimensionamento de um paleocanal soterrado na calha de um rio intermitente da região nordeste do Brasil. A profundidade máxima dos sedimentos saturados, ao contrário do anteriormente relatado na literatura, chega a atingir até $20 \mathrm{~m}$. O modelo 3D gerado permite visualizar a distribuição espacial dos sedimentos, mostrando as suas irregularidades. Além do paleocanal principal ocorrem canais secundários, especialmente do lado esquerdo do modelo, os quais não podem ser completamente identificados por meio de um programa regular de sondagens.

A identificação do paleocanal principal permite otimizar a locação de poços a serem perfurados com o objetivo de produzir água subterrânea. Isto é de especial importância para a região semiárida do nordeste brasileiro.

\section{Referências}

ALMEIDA FILHO, R.; MIRANDA, F.P. 2007. Mega Capture of the Rio Negro and Formation of the Anavilhanas Archipelago, Central Amazonia, Brazil: Evidences in an SRTM Digital Elevation Model. Remote Sensing of Environment, 110, 387-392.

CPRM. 2000. Companhia de Pesquisa de Recursos Minerais/Serviço Geológico do Brasil. SUMÉ - FOLHA SB.24-Z-D-V. Brasília - DF.

FALGÀS, E.; LEDO, J.; BENJUMEA, B.; QUERALT, P.; MARCUELLO, A.; TEIXIDÓ, T.; MARTÍ, A. 2011. Integrating Hydrogeological and Geophysical Methods for the Characterization of a Deltaic Aquifer System. Surv Geophys (2011) 32:857-873.
FRADELIZIO, G. L.; LEVANDER, A.; ZELT, C. A. 2008 Three-dimensional seismic-reflection imaging of a shallow buried paleochannel. Geophysics (2008) 73 (5): B85-B98.

GENAU, R. B.; MADSEN, J. A.; MCGEARY, S.; WEHMILLER, J. F. 1994 Seismic-Reflection Identification of Susquehanna river Paleochannels on the Mid-Atlantic Coastal Plain. Quaternary Research, 42, 166-175.

GILVEAR, D.; BRYANT, R. G. 2003. Analysis of Aerial Photography and Other Remotely Sensed Data. In: KONDOLF, G. M.; PIEGAY, H (ed.). Tools in Fluvial Geomorphology, Chichester: Wiley, pp. 135-170.

ISLAM, Z.U.; IQBAL, J.; KHAN, J.A.; QAZI, W.A. 2016 Paleochannel delineation using Landsat $8 \mathrm{OLI}$ and Envisat ASAR image fusion techniques in Cholistan desert, Pakistan. J. Appl. Remote Sensing 10(4), 046001, doi: 10.1117/1. JRS.10.046001.

KAFRI, U.; GOLDMAN, M. 2005. The use of the time domain electromagnetic method to delineate saline groundwater in granular and carbonate aquifers and to evaluate their porosity. J Appl Geophys 57(3): 167-178.

KRIVOCHIEVA, S.; CHOUTEAU, M. 2003. Integrating TDEM and MT methods for characterization and delineation of the Santa Catarina aquifer (Chalco SubBasin, Mexico). J Appl Geophys 52(1):23-43.

MEJU, M. A.; GALLARDO, L.; MOHAMED, A. K. 2003. Evidence for correlation of electrical resistivity and seismic velocity in heterogeneous near-surface materials. Geophys Res Lett 30(7):1373.

MOTA, R.; MONTEIRO DOS SANTOS, F. 2006. 2D sections of porosity and water saturation percent from combined resistivity and seismic surveys for hydrogeologic studies. Lead Edge 25:735-737.

PEDERSEN, L. B.; BASTANI, M.; DYNESIUS, L. 2005. Groundwater exploration using combined controlledsource and radiomagnetotelluric techniques. Geophysics 70:G8-G15.

SCHWINN, W.; TEZKAN, B. 1997. 1D joint inversion of radiomagnetotelluric (RMT) and transient electromagnetic (TEM) data; an application for groundwater prospection in Denmark. 3rd EEGS, Arhus.

UNSWORTH, M. J.; LU, X.; WATTS, M. D. 2000. AMT exploration at Sellafield: characterization of a potential radioactive waste disposal site. Geophysics 65:10701079.

VIEIRA, L. J. S. 2002. Emprego de um modelo matemático de simulação do fluxo subterrâneo para definição de alternativas de exportação de um aquífero aluvial.117f. Dissertação (Mestrado em Engenharia Civil e Ambiental) - Universidade Federal de Campina Grande, Campina Grande. 
Depth Iteration 4 RMS error $=29.1 \%$

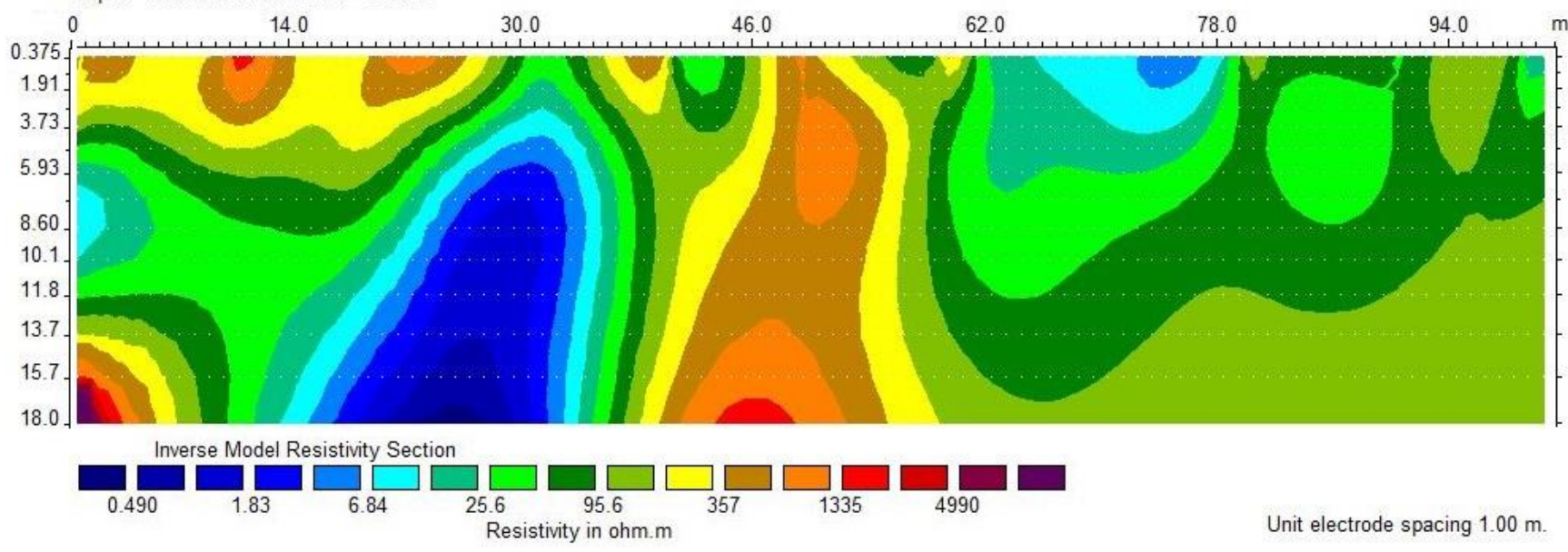

Figura 3 - Seção geoelétrica de resistividade da linha $01(Y=0 \mathrm{~m})$.

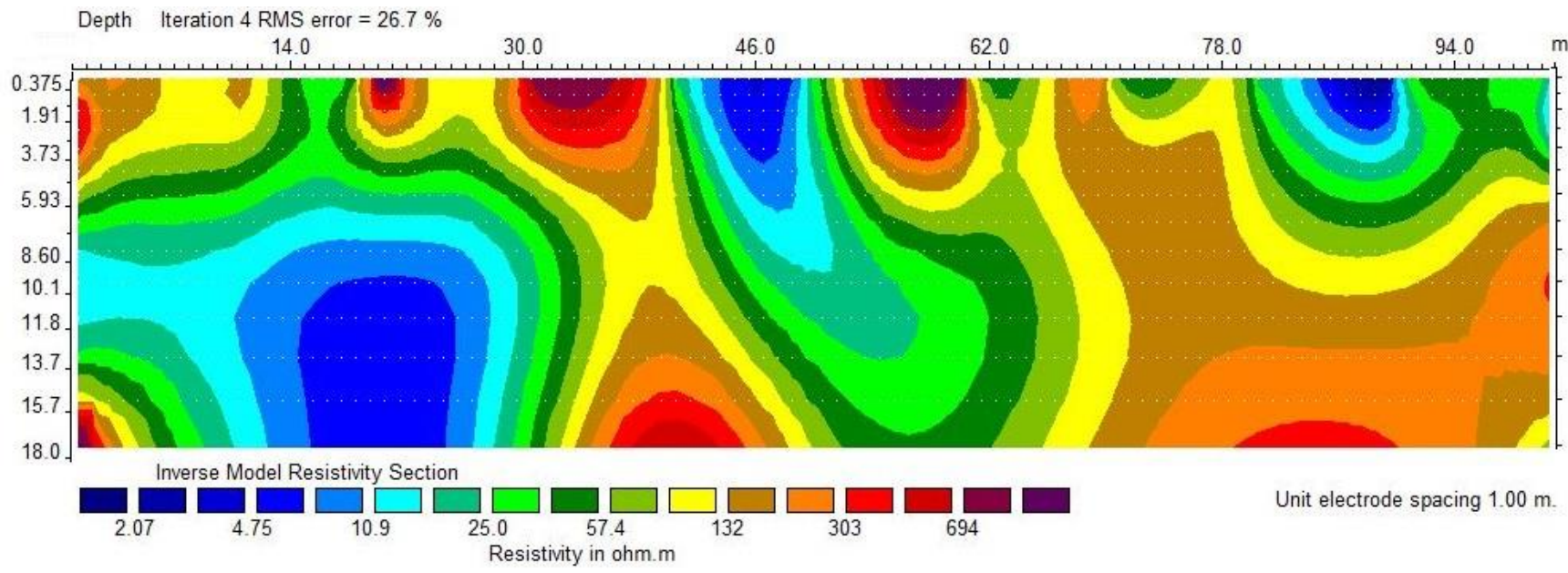

Figura 4 - Seção geoelétrica de resistividade da linha $02(Y=25 \mathrm{~m})$.

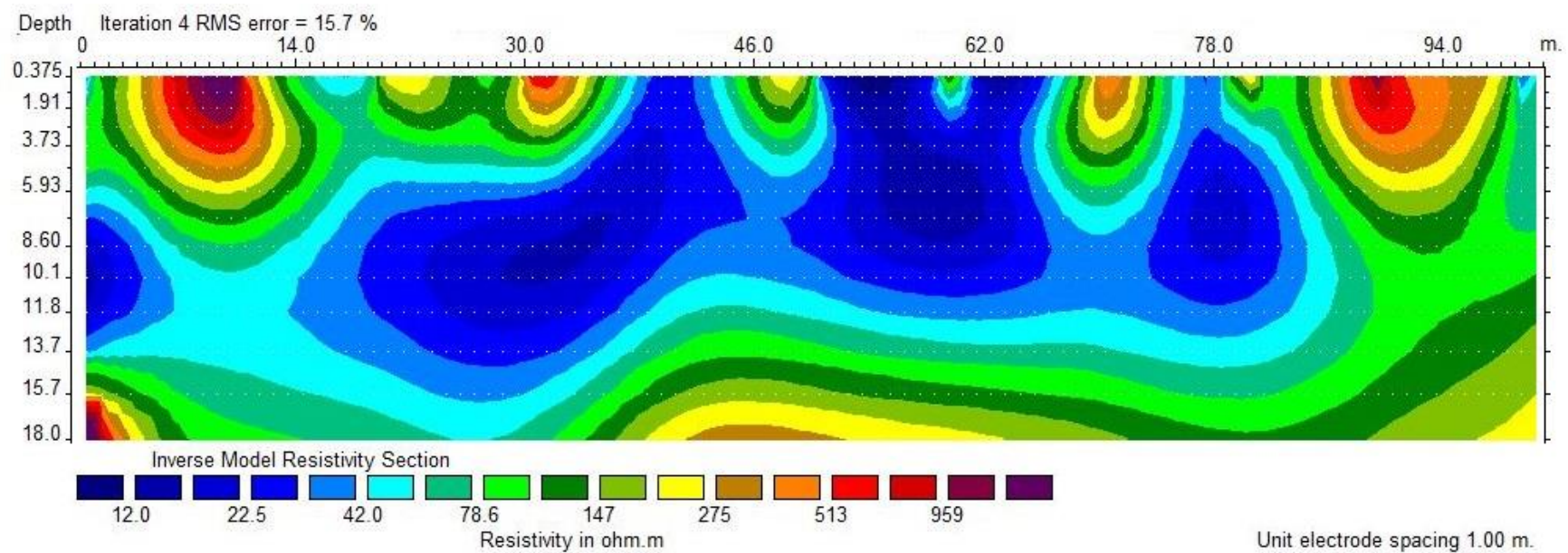

Figura 5 - Seção geoelétrica de resistividade da linha $03(Y=50 \mathrm{~m})$. 


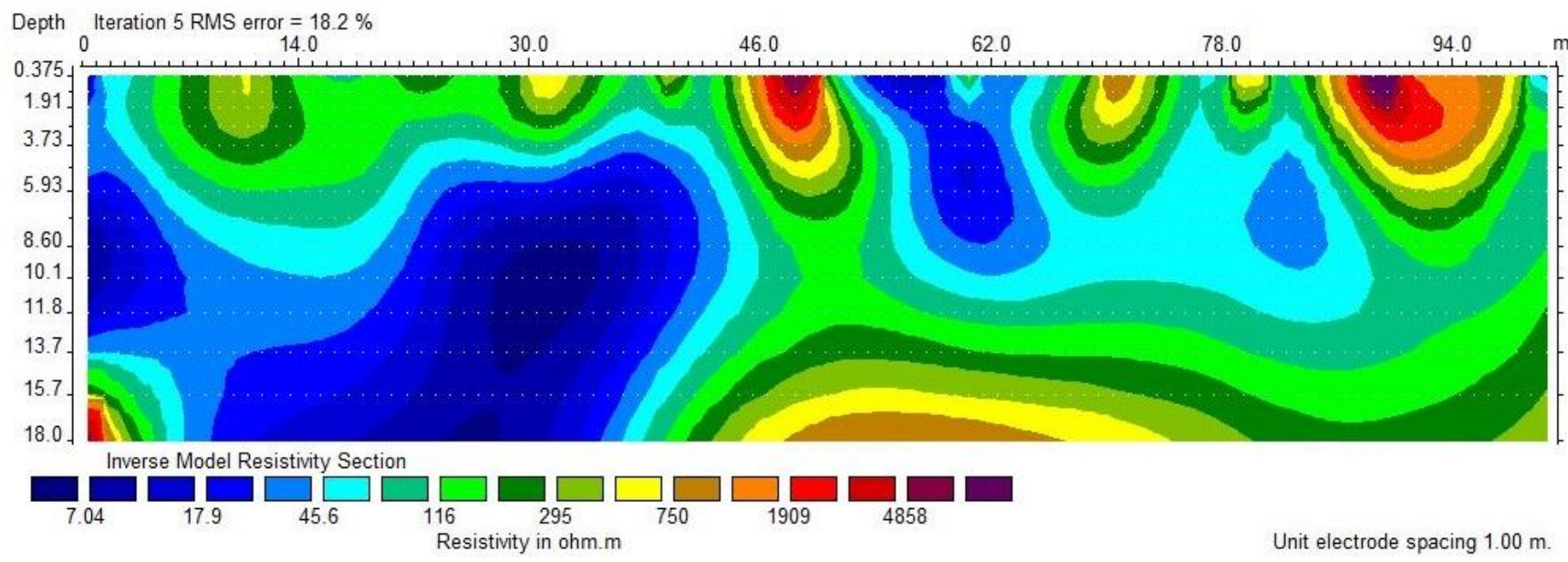

Figura 6 - Seção geoelétrica de resistividade da linha $04(Y=75$ m).

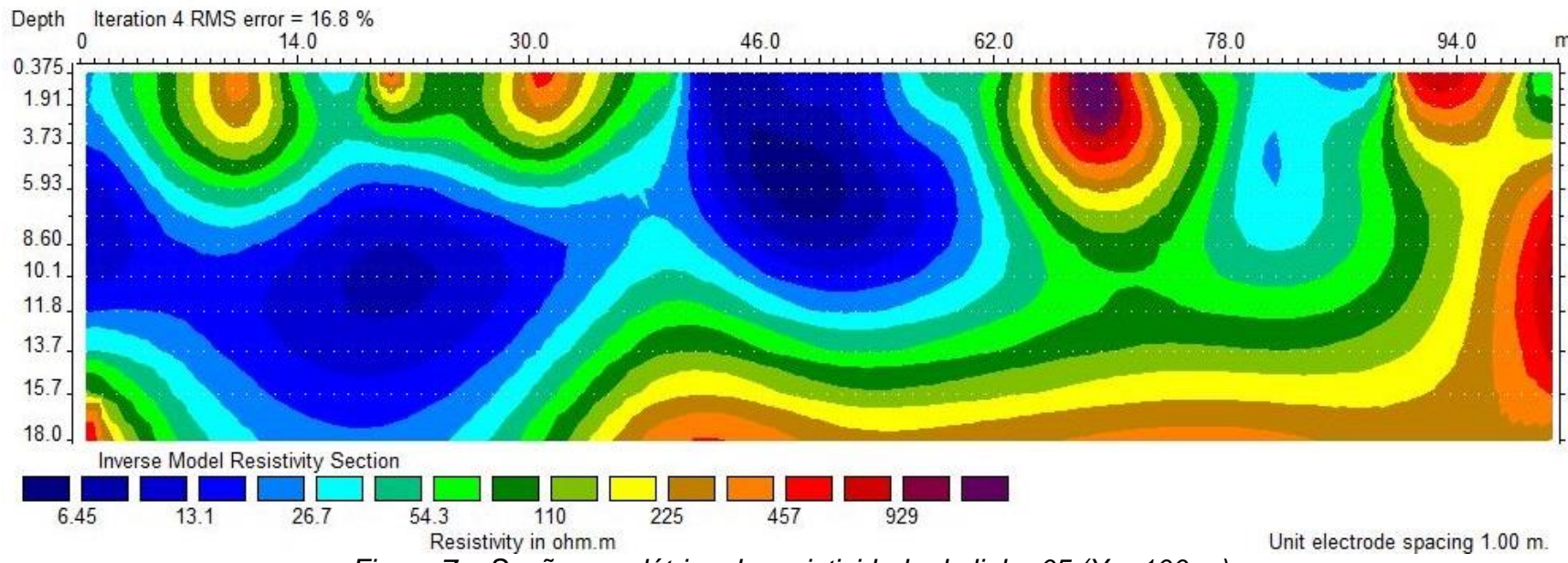

Figura 7 - Seção geoelétrica de resistividade da linha $05(Y=100 \mathrm{~m})$.

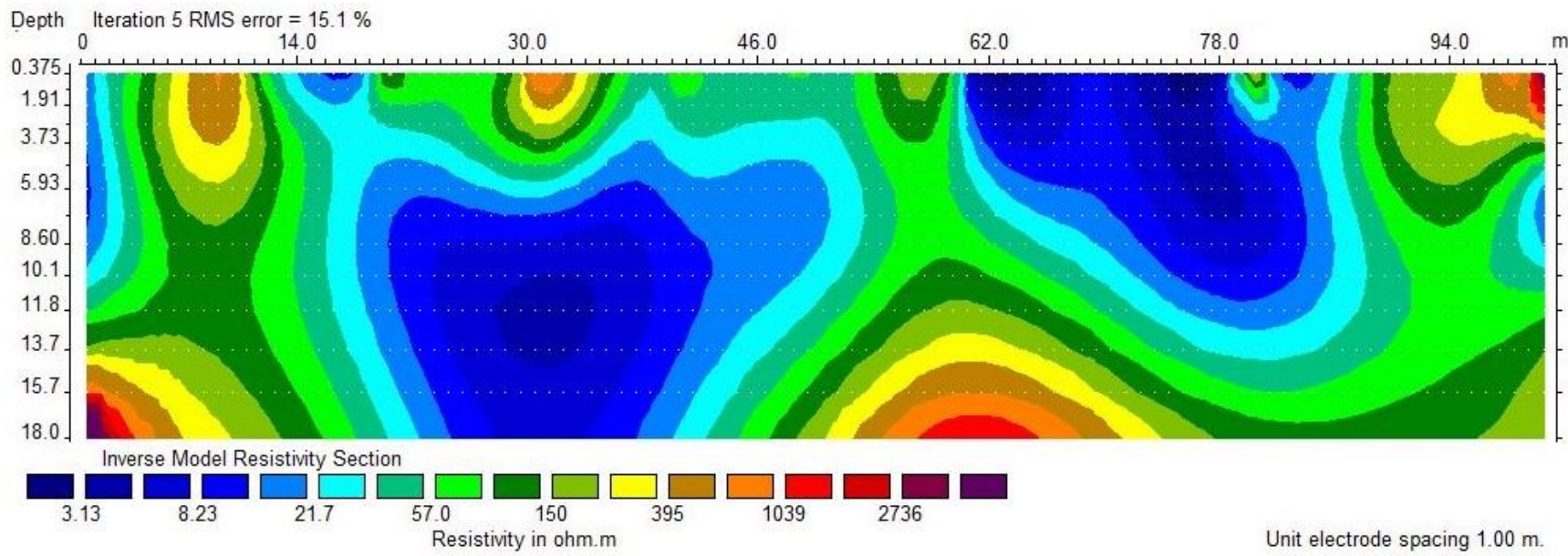

Figura 8 - Seção geoelétrica de resistividade da linha $06(Y=125 \mathrm{~m})$. 


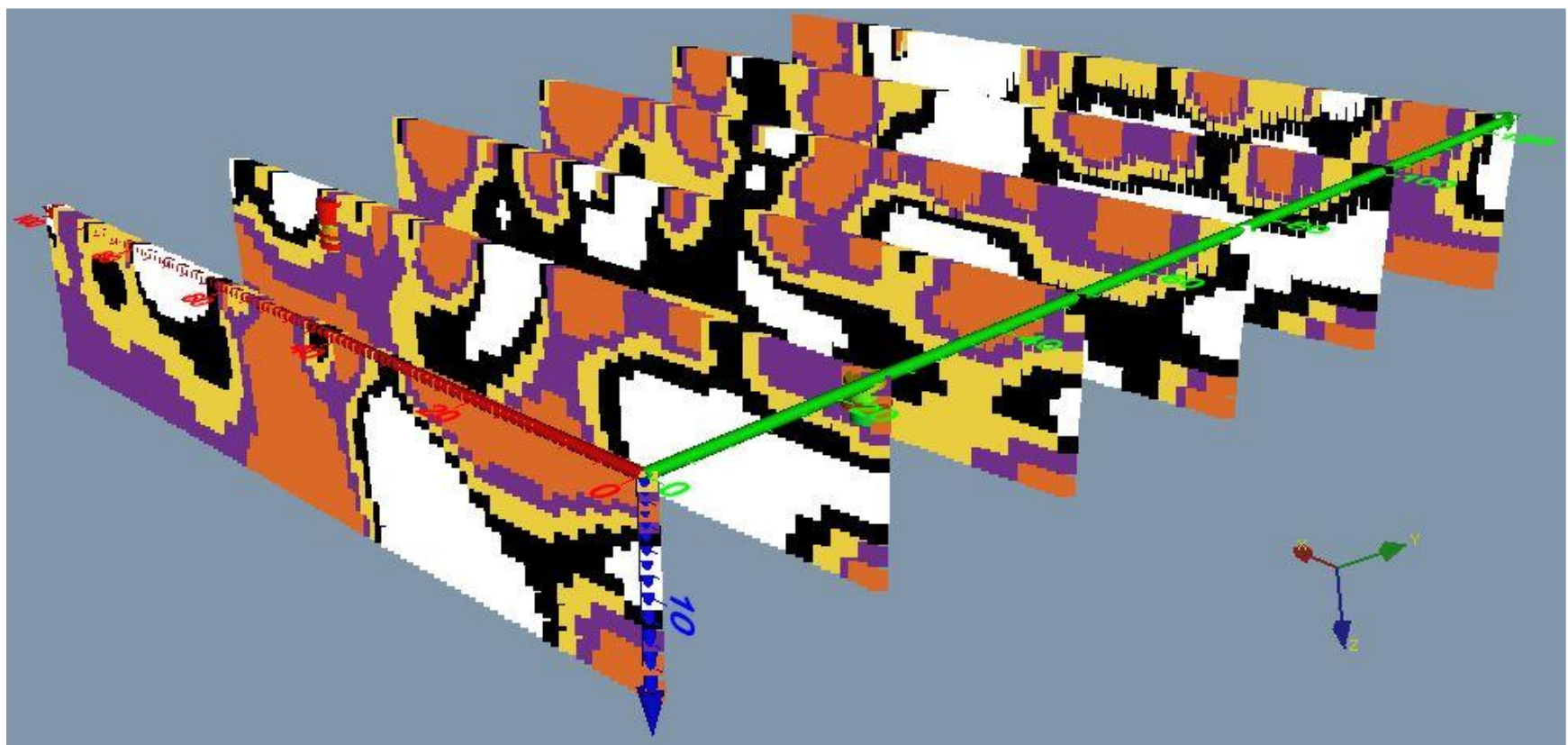

Figura 9 - Conjunto de seções geoelétricas visualizadas no software utilizado para interpolação.

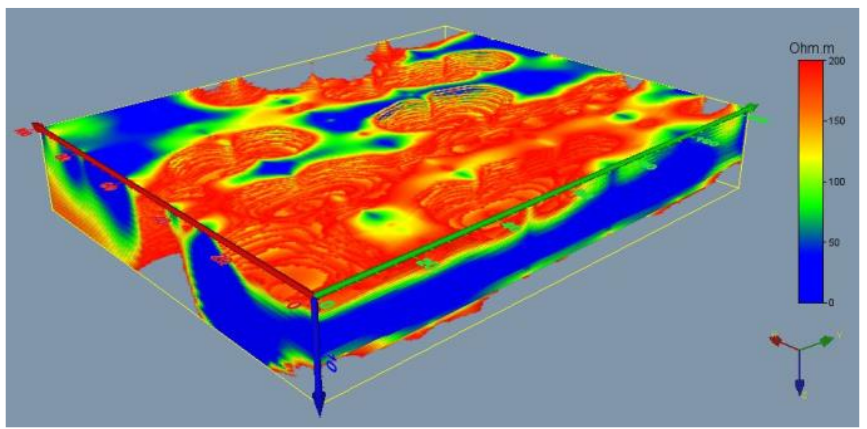

Figura 10 - Modelo $3 D$ de resistividade elétrica da área de estudo.

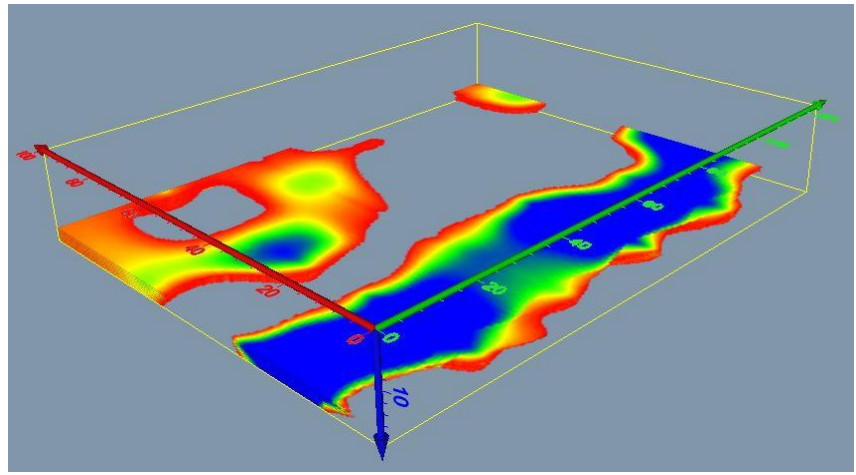

Figura 12 - Corte do modelo 3D de resistividade elétrica na profundidade de $17 \mathrm{~m}$.

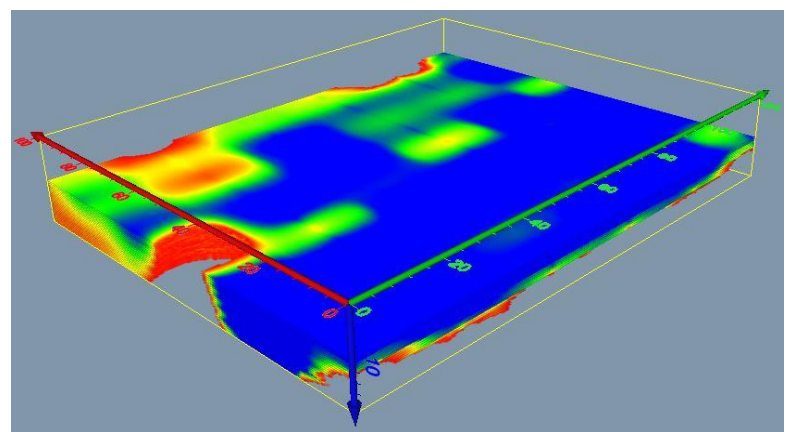

Figura 11 - Corte do modelo 3D de resistividade elétrica na profundidade de $10 \mathrm{~m}$.

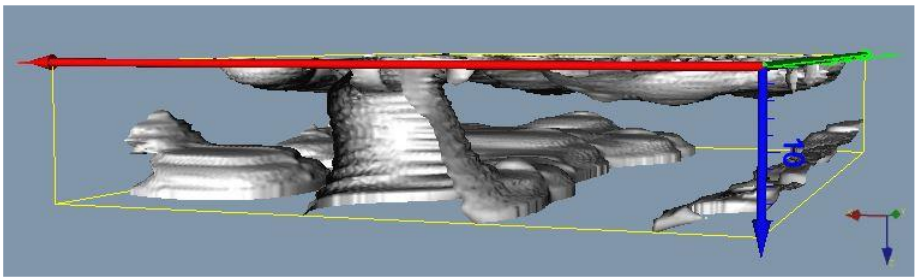

Figura 13 - Superfícies de resistividade elétrica maiores que 200 ohm.m. Nesta figura observa-se o paleocanal claramente indicado na parte inferior direita, o topo do embasamento à esquerda e à direita do paleocanal e a zona resistiva superficial que corresponde à zona acima do nível d'água. 